\title{
Scoping the Problem
}

In this issue of our journal, Encinas-Latoy, et al., report on the diagnostic yield of bronchoscopic techniques in evaluating primary lung cancer. ${ }^{1}$ Fiberoptic bronchoscopy is an important diagnostic modality for lung cancer which remains a major global and national health problem. New cases of lung cancer ranked number one, comprising $11.6 \%$ of the total 18 million new cases of cancer globally, ${ }^{2,3}$ Lung cancer also accounted for the greatest number of deaths due to malignancy with 1.8 million persons. In the Philippines, it was estimated that there were 109,280 new cases of cancer with 66,151 cancer deaths in 2015. ${ }^{4}$ Of these, lung cancer remains the most common cause of new cases (12.5\%) and deaths (17.8\%). Many patients with lung cancer do not survive within a year following diagnosis with a five-year survival rate in Metro Manila patients being just $12 \%$ lower than the global average for that time.

Diagnosis of lung cancer, therefore, remains a top priority in our country. But primary lung cancer describes a heterogeneous group of malignancies. ${ }^{5-7}$ The most common group, traditionally called bronchogenic carcinomas arising from the bronchial airways are classically grouped into the small and non-small cell types as well as many mixed types in between. These are the cancers that are more likely accessible by fiberoptic bronchoscopy since they occur in the airways. However, as the authors also mention, those lesions that are more centrally-located, i.e., those in the bigger airways, are the ones more likely to be detected by bronchoscopy since they are the ones that can be reached by an endoscope of a certain diameter.

And that is where the term diagnostic yield can get quite complex. Similar to other diagnostic procedures, how patients are selected to undergo the procedure can determine how many are eventually diagnosed. In bronchogenic carcinomas, the diagnostic objective is not only to verify the malignant nature of the pulmonary mass but to get biopsy confirmation of its histologic type because the choice of treatment is highly dependent on the histologic types and sub-types. The authors cite a figure of $86 \%$ diagnostic yield which at first glance makes it an attractive diagnostic step of first choice. But as the authors also mention, not all patients with pulmonary mass and suspicion of lung malignancy were subjected to bronchoscopy. According to the mentioned institutional practice, patients with "a more central location, at least 1 to $2 \mathrm{~cm}$ in size, and located near an airway..." are selected for bronchoscopy. Rightfully so, lesions that are nearer the carina have long been previously described to predict a higher diagnostic yield. ${ }^{8-10}$ That patient profile alone can significantly increase the diagnostic yield. However, the authors did not specifically state that fiberoptic bronchoscopy in the study was limited only to those patients who were found to have centrally-located masses. If so, with a diagnostic yield of $86 \%$, it would suggest that fiberoptic bronchoscopy may also fail to diagnose all instances of centrally-located lesions. It may therefore help to describe the patient factors among those that have centrally-located masses but yielded negative on fiberoptic bronchoscopy. Missing the diagnosis of malignancy can be a serious matter especially in lung cancer where early diagnosis can make a difference. ${ }^{11-13}$

Similarly, it was reported that 7 cases who underwent flexible bronchoscopy were diagnosed benign and another 7 were reported as non-diagnostic. These were eventually found out to have malignancy by other means. It would again be of interest to find out the profile of these patients who had lung malignancy but who were not diagnosed on fiberoptic bronchoscopy.

The authors also mention that they have excluded about 21 cases who underwent bronchoscopy but whose diagnoses of malignancy were never confirmed. Understandably, because of the retrospective nature of the study, such information could not be located or verified anymore. If these cases turned out to have malignancy, the diagnostic yield would have come down to just a little above 70\% (86/121). In an ideal diagnostic sensitivity study, a "gold standard" other than the diagnostic test itself should be used to determine the test's performance. In a diagnostic procedure with several stakeholders who may have their own "diagnostic yields" (e.g., the clinician who suspected the first diagnosis, the other imaging studies which would prompt a decision to do a bronchoscopy, the one who does the procedure itself, and the pathologist who interprets the cytology or histology specimen), there are many other potential confounding variables that can affect the test's real performance or diagnostic yield.

Strictly defining a gold standard, therefore, is very important. Perhaps as the authors suggest, a well-designed prospective study would be a better way to measure the real diagnostic yield of fiberoptic bronchoscopy in this particular institution. Such a prospective study should control or mitigate the various other stakeholder decisions that can influence the diagnostic yield ultimately attributed to fiberoptic bronchoscopy. This will help clinicians identify better the type of patient for whom the procedure would indeed provide the most value - an aspiration that translates well in improving patient care in a setting with limited resources. In addition, as a training institution of the University of the Philippines - Philippine General Hospital, accurate measures, and trends of procedural tests such as fiberoptic bronchoscopy performed by the trainees can be used to measure the quality and outcomes of its training programs.

Studies on the diagnostic yield of fiberoptic bronchoscopy should not only involve looking into making the correct diagnosis that guides the proper management of lung cancer. Data should also include metrics on the safety of patients who underwent the procedure. Fiberoptic bronchoscopy is a relatively safe procedure if done properly, but several adverse events must be 
anticipated and avoided. ${ }^{14,15}$ It is not an innocuous procedure with some of the adverse events being potentially fatal. Reporting adverse events in this study could therefore be helpful as it could instruct ways to avoid such adverse events in the future.

The introduction of fiberoptic endoscopy has truly allowed improvements in patient care where they are used, not only in lung diseases but also in many others. For fiberoptic bronchoscopy, there have been numerous recent enhancements being done that could improve its diagnostic yield. Among these are endobronchial ultrasound (EBUS), CT-guided bronchoscopy, and others. ${ }^{16-24}$ Innovations involving the processing of bronchoscopy specimens such as immunohistochemistry and other molecular tests can likewise improve indirectly the diagnostic yield and accuracy from fiberoptic bronchoscopy by making more definitive diagnosis even from smaller amounts of tissue samples. ${ }^{25-29}$ It is hoped that all of these can be included as appropriate in the future endeavors to improve the diagnostic yield of fiberoptic bronchoscopy in this premiere institution.

\author{
Joven Jeremius Q. Tanchuco, MD, MHA \\ Professor, Department of Biochemistry and Molecular Biology, \\ College of Medicine, University of the Philippines Manila \\ Clinical Professor, Division of Pulmonary Medicine, Department of Medicine, \\ College of Medicine and Philippine General Hospital, University of the Philippines Manila
}

\section{REFERENCES}

1. Encinas-Latoy MAM, Masalunga MC, Angeles RRB, Tojino AKG. Diagnostic Yield of Bronchoscopic Techniques in Evaluating Primary Lung Cancer: The Philippine General Hospital (PGH) Experience. Acta Med Philipp. 2021; 55(4):467-472. https://doi.org/10.47895/amp.vi0.2794 _

2. Globocan 2018. International Agency for Research on Cancer [Internet]. May 2019 [cited 2021 Jul 12]. Available from: http://gco.iarc.fr/today/data/factsheets/ populations/900-world-fact-sheets.pdf

3. Bray F, Ferlay J, Soerjomataram I, Siegel RL, Torre LA, Jemal A. Global cancer statistics 2018: GLOBOCAN estimates of incidence and mortality worldwide for 36 cancers in 185 countries. CA Cancer J Clin. 2018; 68(6):394-424. https:// doi.org/10.3322/caac. 21492

4. Laudico AV, Mirasol-Lumague MR, Medina V, Mapua CA, Valenzuela FG, Pukkala E. 2015 Philippine Cancer Facts and Estimates [Internet]. [cited $2021 \mathrm{Jul}$ 12]. Available from: http://www.philcancer.org.ph/wp-content/ uploads/2017/07/2015-PCS-Ca-Facts-Estimates_CAN090516.pdf

5. Travis WD, Brambilla E, Nicholson AG, Yatabe Y, Austin JHM, Beasley M, et al. The 2015 World Health Organization Classification of Lung Tumors: Impact of Genetic, Clinical and Radiologic Advances Since the 2004 Classification. J Thorac Oncol. 2015; 10(9): 1243-1260. https://doi.org/10.1097/ JTO.0000000000000630

6. de Sousa VML, Carvalho L. Heterogeneity in Lung Cancer. Pathobiology. 2018; 85(1-2):96-107. https://doi.org/10.1159/000487440

7. Zito Marino F, Bianco R, Accardo M, Ronchi A, Cozzolino I, Morgillo F, et al. Molecular heterogeneity in lung cancer: from mechanisms of origin to clinical implications. Int J Med Sci. 2019; 16(7):981-989. https://doi.org/10.7150/ ijms.34739

8. Roth K, Hardie JA, Andreassen AH, Leh F, Eagan TMI. Predictors of diagnostic yield in bronchoscopy: a retrospective cohort study comparing different combinations of sampling techniques. BMC Pulm Med. 2008; 8:2. https://doi. org/10.1186/1471-2466-8-2

9. Boonsarngsuk V, Raweelert P, Sukprapruet A, Chaiprasithikul R, Kiatboonsri S. Factors affecting the diagnostic yield of flexible bronchoscopy without guidance in pulmonary nodules or masses. Singapore Med J. 2010; 51(8):660-665.

10. Karahalli E, Yilmaz A, Türker H, Ozvaran K. Usefulness of various diagnostic techniques during fiberoptic bronchoscopy for endoscopically visible lung cancer: should cytologic examinations be performed routinely? Respiration. 2001; 68(6):611-614. https://doi.org/10.1159/000050581

11. Jones GS, Baldwin DR. Recent advances in the management of lung cancer. Clin Med (Lond). 2018;18(Suppl 2):s41-s46. https://doi.org/10.7861/ clinmedicine.18-2-s41

12. Inage T, Nakajima T, Yoshino I, Yasufuku K. Early Lung Cancer Detection. Clin Chest Med. 2018;39(1):45-55. https://doi.org/10.1016/j.ccm.2017.10.003

13. Du Rand IA, Blaikley J, Booton R, Chaudhuri N, Gupta V, Khalid S, et al. British Thoracic Society guideline for diagnostic flexible bronchoscopy in adults: accredited by NICE. Thorax. 2013; 68 Suppl1:i1-i44. https://doi.org/10.1136/ thoraxjnl-2013-203618.

14. Latimer KM, Mott TF. Lung cancer: diagnosis, treatment principles, and screening. Am Fam Physician. 2015;91(4):250-256.
15. Qanash S, Hakami O A, Al-Husayni F, Gari AG. Flexible Fiberoptic Bronchoscopy: Indications, Diagnostic Yield and Complications. Cureus. 2020; 12(10): e11122. https://doi.org/10.7759/cureus.11122

16. Cheng G, Mahajan A, Oh S, Benzaquen S, Chen A. Endobronchial ultrasoundguided intranodal forceps biopsy (EBUS-IFB)-technical review. J Thorac Dis. 2019; 11(9), 4049-4058. https://doi.org/10.21037/jtd.2019.08.106

17. Ali MS, Trick W, Mba BI, Mohananey D, Sethi J, Musani AI. Radial endobronchial ultrasound for the diagnosis of peripheral pulmonary lesions: A systematic review and meta-analysis. Respirology. 2017; 22(3):443-453. https://doi.org/10.1111/resp.12980

18. Vaidya PJ, Munavvar M, Leuppi JD, Mehta AC, Chhajed PN. Endobronchial ultrasound-guided transbronchial needle aspiration: Safe as it sounds. Respirology. 2017; 22(6):1093-1101. https://doi.org/10.1111/resp.13094

19. Sakairi Y, Nakajima T, Yoshino I. Role of endobronchial ultrasound-guided transbronchial needle aspiration in lung cancer management. Expert Rev Respir Med. 2019; 13(9):863-870. https://doi.org/10.1080/17476348.2019.1646642

20. Fu YF, Zhang JH, Wang T, Shi YB. Endobronchial ultrasound-guided versus computed tomography-guided biopsy for peripheral pulmonary lesions: A metaanalysis. Clin Respir J. 2021; 15(1):3-10. https://doi.org/10.1111/cri.13275

21. Righi L, Franzi F, Montarolo F, Gatti G, Bongiovanni M, Sessa F, et al. Endobronchial ultrasound-guided transbronchial needle aspiration (EBUSTBNA)-from morphology to molecular testing. J Thorac Dis. 2017; 9(Suppl 5):S395-S404. https://doi.org/10.21037/jtd.2017.03.158

22. Ishiwata T, Gregor A, Inage T, Yasufuku K. Bronchoscopic navigation and tissue diagnosis. Gen Thorac Cardiovasc Surg. 2020; 68(7):672-678. https:// doi.org/10.1007/s11748-019-01241-0

23. Kemp SV. Navigation Bronchoscopy. Respiration. 2020; 99(4):277-286. https://doi.org/10.1159/000503329

24. de Margerie-Mellon C, de Bazelaire C, de Kerviler E. Image-guided biopsy in primary lung cancer: Why, when and how. Diagn Interv Imaging. 2016; 97(10):965-972. https://doi.org/10.1016/j.diii.2016.06.016

25. Inamura K. Update on Immunohistochemistry for the Diagnosis of Lung Cancer. Cancers. 2018; 10(3):72. https://doi.org/10.3390/cancers10030072

26. Bodor JN, Boumber Y, Borghaei H. Biomarkers for immune checkpoint inhibition in non-small cell lung cancer (NSCLC). Cancer. 2020; 126(2): 260-270. https://doi.org/10.1002/cncr.32468

27. Lindeman NI, Cagle PT, Aisner DL, Arcila ME, Beasley MB, Bernicker EH, et al. Updated Molecular Testing Guideline for the Selection of Lung Cancer Patients for Treatment With Targeted Tyrosine Kinase Inhibitors: Guideline From the College of American Pathologists, the International Association for the Study of Lung Cancer, and the Association for Molecular Pathology. Arch Pathol Lab Med. 2018; 142(3): 321-346. https://doi.org/10.5858/arpa.2017-0388-CP

28. Osmani L, Askin F, Gabrielson E, Li QK. Current WHO guidelines and the critical role of immunohistochemical markers in the subclassification of non-small cell lung carcinoma (NSCLC): Moving from targeted therapy to immunotherapy. Semin Cancer Biol. 2018; 52(Pt 1):103-109. https://doi. org/10.1016/j.semcancer.2017.11.019

29. Jain D, Nambirajan A, Borczuk A, Chen G, Minami Y, Moreira AL, et al. Immunocytochemistry for predictive biomarker testing in lung cancer cytology. Cancer Cytopathol. 2019; 127(5):325-339. https://doi.org/10.1002/cncy.22137 